\title{
Management of Opioid Abuse Epidemic by Introducing Complementary and Alternative Medicine
}

\author{
Feng Feng*, April Horstman-Reser, Jeanine Kernen, Dean Manternach and Harsha Sharma \\ Department of Cardiology, Nebraska Methodist College, China
}

*Corresponding author: Feng Feng, Department of Cardiology, Nebraska Methodist College, China

To Cite This Article: Feng Feng, April Horstman-Reser, Jeanine Kernen, Dean Manternach, Harsha Sharma. Management of Opioid Abuse Epidemic by Introducing Complementary and Alternative Medicine. Am J Biomed Sci \& Res. 2021 - 14(1). AJBSR.MS.ID.001957.

DOI: 10.34297/AJBSR.2021.14.001957.

Received: 眥 August 11, 2021; Published: 制 September 07, 2021

\section{Introduction}

The opioid crisis is an ongoing epidemic in United States. During the COVID-19 pandemic, many patients' access to pain management is restricted. COVID-19 halted much clinical research on pain management and opioid abuse prevention. Possible medical and psychiatric comorbid conditions may significantly increase opioid abuse rates. Opioid abuse may amplify acute respiratory failure risks and impact immunity response to COVID 19, additionally, some drug interactions may lead to unexpected severe adverse effects Schimmel et al. [1] There has been an increase in use of Complementary and Alternative Medicine (CAM) [2] in patients using opioids for chronic pain, however, the evidence to support its use is either limited or lacking Hassan, et al. [3-5]. More than $30 \%$ of adults and about $12 \%$ of children in the U.S. use CAM. CAM is defined as a non-mainstream practice used together with conventional medicine (complementary medicine) or replacing conventional medicine (alternative medicine) (NCCIH, 2017). There are limited evidence-based CAM treatments that adequately control chronic pain, even fewer on analgesic reduction. Our previous study evaluates the effectiveness and limitations of CAM treatments in prevention and treatment of chronic pain along with analgesic reduction. There is a growing discussion exploring roles of Complementary and Alternative Medicine (CAM) in chronic pain management and opioid abuse prevention. Most CAM therapies are free and self-guided with no adverse effects. Our ongoing study has provided evidence on the effectiveness of CAM in improving community health awareness and offers nonpharmacological interventions in prevention of opioid abuse and recovery. We hope to find that pandemic-affected communities can gain knowledge and a positive attitude after CAM training. After education sessions, community participants will hopefully realize the importance of communication with their providers, and the risk and benefits associated with CAM. After six of our experimental sessions of CAM education and treatments, participant's pain level and opioid usage did decrease significantly. We hope the outcomes show successful intervention in a lock-down community population without easy access to healthcare, and that the general public is educated on the potential benefits of CAM. As healthcare educators, it is our goal to address community needs through teaching and allow students to access public healthcare interventions.

\section{References}

1. Schimmel J, Manini AF (2020) Opioid Use Disorder and COVID-19: Biological plausibility for worsened outcomes. Substance Use \& Misuse 55(11): 1900-1901.

2. (2020) Complementary, Alternative, or Integrative Health: What's in a Name?

3. Hassan S, Zheng Q, Rizzo E, Tezcanli E, Bhardwaj S, et al. (2020) Does integrative medicine reduce prescribed opioid use for chronic pain? A systematic literature reviews. Pain Med 21(4): 836-859.

4. Chou L, Ranger TA, Peiris W, Cicuttini FM, Urquhart DM, et al. (2018) Patient's perceived needs for medical services for non-specific low back pain: A systematic scoping review. Plos One 13(11): 0204885.

5. Hart J, Pastore G, Jones M, Barker A, Khosa J, et al. (2016) Chronic orchialgia after surgical exploration for acute scrotal pain in children.

6. Penney LS, Ritenbaugh C, Elder C, Schneider J, Deyo RA, et al. (2015) Primary care physicians, acupuncture and chiropractic clinicians, and chronic pain patients: A qualitative analysis of communication and care coordination patterns. BMC Complementary and Alternative Medicine. 16(1): 30 . 